OPEN ACCESS

Edited by:

Lino Nobili,

University of Genova, Italy

Reviewed by:

Pablo Torterolo,

Universidad de la República, Uruguay

Bjoern Rasch,

Université de Fribourg, Switzerland

${ }^{*}$ Correspondence:

Ravinder Jerath

rj605r@aol.com

Specialty section:

This article was submitted to

Sleep and Chronobiology,

a section of the journal

Frontiers in Psychiatry

Received: 07 September 2018 Accepted: 27 December 2018

Published: 29 January 2019

Citation:

Jerath $R$, Beveridge $C$ and Barnes VA (2019) Self-Regulation of Breathing as an Adjunctive Treatment of Insomnia.

Front. Psychiatry 9:780.

doi: 10.3389/fpsyt.2018.00780

\section{Self-Regulation of Breathing as an Adjunctive Treatment of Insomnia}

\author{
Ravinder Jerath ${ }^{1 *}$, Connor Beveridge ${ }^{1}$ and Vernon A. Barnes ${ }^{2}$ \\ ${ }^{1}$ Charitable Medical Healthcare Foundation, Augusta, GA, United States, ${ }^{2}$ Department of Pediatrics, Georgia Prevention \\ Institute, Augusta University, Augusta, GA, United States
}

Sleep is a quiescent behavioral state during which complex homeostatic functions essential to health and well-being occur. Insomnia is a very common psychiatric disorder leading to a myriad of detrimental effects including loss of concentration, memory, and performance as well as disease. Current pharmaceutical treatments can be expensive, impairing, unhealthy, and habit-forming. Relaxation techniques, such as meditation target the brain and body in contrast to pharmaceutical interventions which solely target neurotransmitter systems in the brain. In this article we present a viewpoint on the treatment of insomnia that techniques of slow, deep breathing $(0.1 \mathrm{~Hz})$ in adjunct to sleep hygiene and relaxation therapies may be highly effective in initiating sleep as well as facilitating falling back asleep. The autonomic nervous system is integral to sleep initiation, maintenance, and disruption. Understanding the relationship between the autonomic nervous system and sleep physiology along with the nature of sleep itself remains a challenge to modern science. We present this perspective in light of a prevailing "dysevolution" theory on the pathology of insomnia that proposes hyper-arousal characterized in part by chronic sympathetic hyperactivation and/or parasympathetic hypoactivation disrupts normal sleep onset latency, sleep quality, and sleep duration. We additionally discuss physiological mechanisms responsible for the effectiveness of the breathing treatment we describe. A better understanding of these mechanisms and autonomic pathologies of insomnia may provide support for the effectiveness of such techniques and provide relief to sufferers of this health epidemic.

Keywords: insomnia, autonomic nervous system, hyper-arousal, evolutionary mismatch hypothesis, paced breathing, slow breathing, cardiorespiratory synchronization

\section{INTRODUCTION}

Sleep is an essential behavioral and neurological state characterized by an absence of response to external stimuli due to temporary periods of unconsciousness along with distinct electroencephalography $(\mathrm{EEG})$ changes $(1,2)$. Although some physiological roles of sleep have been proposed, the definitive function of sleep remains a mystery (3). The average adult needs seven or more hours of sleep per night to maintain optimal health and well-being (4). Adults who consistently get $<7 \mathrm{~h}$ per night are more likely to be obese (5), physically inactive, active smokers, have heart disease (6), asthma, depression, diabetes, and other illnesses (7). More than a third of American adults get $<7 \mathrm{~h}$ of sleep on a regular basis, resulting in sleep deprivation being considered a public health epidemic (8). Globally, $35 \%$ to $50 \%$ of the adult population exhibit some insomnia symptoms (9). Our culture of sleep-deprivation is in part provoked by light bulbs, 
computers, and hectic schedules giving us need and opportunity to stay awake in an ever-more restless world. Objective sleep measure and physiological findings have revealed that many cases of insomnia are a result of a disorder of hyper-arousal present during the day and nighttime (10-13) resulting in physiologic activation (14). In this perspective article, we support a prevailing model of insomnia, the hyper-arousal model, to describe the pathology of insomnia focusing on the autonomic component of this hyper-arousal and how it may be attenuated.

It is estimated that 109,000 vehicular crashes resulting in injury and 6,400 crashes resulting in a fatality occur in the U.S. every year which involve a drowsy driver (15). Sleep deprivation has been reported to cost the U.S. $\$ 411$ billion every year through decreases in productivity and absence from work, not including medical and other costs (16). Clearly, there are vast health and economic losses that may be rectified with the right approaches. Around 4\% of Americans take prescription hypnotic sleep aids, such as Z-drugs and benzodiazepines (17). These drugs can be habit forming and can disturb sleep patterns and sleep architecture $(18,19)$. Other adverse effects include increased risk of injury (20), withdrawal, rebound insomnia (21), suppressed respiration, increased risk of death, depression, traffic collisions, infection, and possibly cancer (22). Our perspective is that reversing disturbed sleep duration and quality induced by the stresses and technologies (23) of modern life with breathing in adjunct to relaxation and sleep-hygiene techniques rather than inundating the brain with hypnotic drugs may be a more effective long-term method to address rampant sleep-deprivation experienced world-wide.

\section{EVOLUTIONARY MISMATCH HYPOTHESIS}

To fully understand the nature of disorders and why they become common, we must harness more information than given by the mechanistic explanations of pathophysiology and investigate the evolutionary origins of disease (24). Evolutionary mismatch hypothesis, or "dysevolution," is a concept in evolutionary biology that describes "mismatch diseases" resulting from evolved traits that were advantageous to an organism's ancestors, but are maladaptive in the current organism due to rapid changes in environment (25-27). Such a rapid and drastic change in organism environment is evident in the dramatic environmental and lifestyle contrast between the several million years of humanoid development and the past 12,000 years of human history spurred by the agricultural and then industrial revolution (28). Many widespread maladies are suggested to be "mismatch diseases" including osteoarthritis $(29,30)$, cardiovascular problems, diabetes, obesity, (26), myopia, and even athlete's foot (27) Although not empirically investigated, insomnia has also been suggested to be the result of such a mismatch (27). An important aspect of the perspective asserted in this article is that such a mismatch is a key component in the pathology of modern insomnia. We support the hypothesis that a significant mismatch between the lifestyles of modern persons and our caveman and animal ancestors has led to dramatic differences in the daily operations of the autonomic nervous system $(28,31)$. In modern times, our frenetic nature has resulted in toxic, long-term activation of the sympathetic nervous system; a system developed by evolutionary mechanisms for short-term stress response $(32,33)$. We propose that this sympathetic hyperactivation and/or parasympathetic hypoactivation may significantly influence the development and maintenance of a significant fraction of modern cases of insomnia (13).

\section{NON-PHARMACOLOGICAL INTERVENTIONS}

Certain non-pharmacological treatments have significant support for effectiveness in managing insomnia and so we stress that slow breathing should be used in adjunct or as a component of these prevailing methods. Sleep Hygiene education and practice are often promoted as a first line of treatment for insomnia due to effectiveness (34-36), low cost, and low risk (37). It includes practices centered around homeostatic (exercising), circadian (altering light exposure), lifestyle (restricting alcohol use), and arousal factors (stress management, restricting caffeine) (38). Relaxation techniques are intended to assist in managing stress and include practices, such as meditation, muscle relaxation, and mental imagery (39). One traditional relaxation model has described the biological induction of the relaxation response as an increase in vagal tone of the autonomic nervous system (ANS) (40). Extensions of the model additionally described cognitive-behavioral components (41). Mental and physical images of forests and other natural imagery may also provoke relaxation and sympathetic inhibition $(42,43)$. Many meditation styles have shown to be an effective relaxation therapy for multiple components of insomnia (44-51). Due to the commonality of sleep improvements across many mediation styles, meditation may be defined generally for sleep medicine purposes as a technique utilizing calm focus of the mind along with self-induced, cognitive and muscular relaxation (52).

\section{STRESS AND THE AUTONOMIC NERVOUS SYSTEM}

Sleep is essential to complex homeostatic functions (53) regulated largely by the ANS (54). As good sleepers transition from wake to sleep, respiratory rate slows and becomes more regular as parasympathetic tone increases $(54,55)$. The majority of those with an ANS disorder also have a sleep disorder (56). Short sleep duration and insomnia have been associated with significantly lower levels parasympathetic activity and/or higher levels of sympathetic activity during daytime rest (57), sleepwake transitions, and overnight sleep (58-60), characteristic of a general hyper-arousal disorder (10). Abnormalities in autonomic modulation may in part explain the elevated risk of cardiovascular disease in insomniacs $(61,62)$. Studies on heart rate variability and insomnia reveal increased sympathetic 
activity while awake before sleep and during stage- 2 nonREM sleep which support the theory that autonomic hyperarousal is a major cause of insomnia $(63,64)$. This state of increased nocturnal autonomic arousal in insomnia patients who are simultaneously exhausted is known in sleep clinics as "tired but wired" (56). Studies on hyper-arousal also show increased nocturnal metabolic rate, increased activation of arousal networks in the brainstem and hypothalamus, and cortical activation during sleep (65). EEG analysis has revealed that insomniacs have increased Beta and Gamma frequency activity during NREM sleep which are frequencies more associated with the waking state (66).

Unexpected and sudden stimuli can provoke the shortterm stress response to protect the animal (67). Sympathetic activation is the main factor in this immediate, defensive response, stimulating the release of stress hormones which can be very harmful with long-term exposure (32). Although shortterm stress may have beneficial components, such as heightened mental alertness and enhanced immunological responses (68), high levels of distress can produce a mental blockage state in which cognition is disorganized and dysfunctional (33). This state can further produce distress which in effect may prod us into a chronically distressed lifestyle (69). In addition to insomnia, long-term distress is associated with a myriad of ailments including reduced immune function (70), mental illness, cardiovascular problems, and even cancer (71). Although the immediate stress response is autonomic, secondary effects, such as those regulated by the HPA-axis occur minutes to hours after a stressor occur. Although out of the scope of this article, these secondary effects are also likely involved in promoting insomnia and so should be included in future directions for investigation into slow breathing, dysevolution, and sleep.

In pre-historic times, our "flight-or-fight" sympathetic response was typically only activated short-term in the presence of predators, enemies, or other immediate dangers (31). However, in our modern frenetic lifestyles we find ourselves in a chronically elevated sympathetic state most likely due to a combination of distress induced by our jobs, tendencies to commit to goals and responsibilities we can't achieve, and sleep deprivation $(31,33)$. In today's world, "The bear is always there." A main point of this article is that this outdated survival development, which has resulted in an impaired state of "sympathoneural hypertonicity" in which our sympathetic system is regularly overactive (72), is a major promoter of sleep deprivation (13). Similar to how distress itself can produce distress, this evolutionary "mismatch disease" may create a vicious cycle where stress leads to insomnia and insomnia leads to more stress. As with other "mismatch diseases," an effective treatment strategy will involve shifting autonomic activity patterns to more closely approximate the patterns which exist in conditions under which our species evolved $(28,29)$.

According to the somatic marker hypothesis and our embodied cognitive perspective, states of the mind may not only affect the body, but states of the body may affect the mind $(73,74)$. Thus, just as states of wakefulness and sleep influence the ANS, the ANS may influence those same states. The "somatic markers" of ANS arousal or relaxation may be recognized by the brain and produce mental arousal or relaxation
(75). Norepinephrine and epinephrine are the main hormones used by the sympathetic nervous system that when released into the blood stream, act widely across the body that promote active body movement, alertness, and arousal (76). The increased circulating norepinephrine in insomniacs may inhibit sleep (58). In contrast, the effects of the parasympathetic nervous system are mediated by acetylcholine which promotes rest and relaxation (77). Our perspective is that the strong bodily arousal/relaxation induced by the ANS can stimulate mental arousal/relaxation. Thus, by promoting physiological relaxation or arousal, we assert that the state of the ANS can influence sleep. More research into how the ANS can influence mental states is needed to determine if relaxation therapies work by modulating the ANS directly or if ANS modulation is an indirect effect.

With practice of slow, deep breathing, one may attenuate this autonomic hyper-arousal and be more relaxed when it is time to sleep. Due to slow-wave sleep promoting parasympathetic tone (78), developing a regular, healthy sleep cycle would additionally stabilize the hyper-aroused autonomic tone to a calmer state. Although deep breathing is the most commonly used relaxation technique for insomnia, few studies have empirically investigated a connection between slow breathing and insomnia (79). Tsai et al. suggested that indeed autonomic dysfunction is often a part of the pathology of insomnia and reported that slow breathing can increase vagal tone resulting in improved sleep quality (13). Research is needed on the pathology of "sympathoneural hypertonicity" in insomnia, and we additionally suggest investigation into the connection between the increases in NREM beta/gamma activity in poor sleepers and autonomic dysfunction as both may play a role in mediating the relationship between insomnia and distress.

\section{CARDIORESPIRATORY SYNCHRONIZATION}

Cardiorespiratory synchronization (CS) is an interaction in which the heart rate and breathing pattern synchronize (80). In a previous article, we discussed how the CS that occurs during slow-wave sleep assists in the restorative function of sleep (81, 82). This synchronization is directly associated with an increase in parasympathetic tone observed during NREM sleep (78). Such interaction is bi-directional as CS is strongly influenced by autonomic tone (83). We support the view that voluntarily fostering CS can influence the ANS toward parasympathetic dominance (13) and may provide some restorative function needed after sleep loss (82). Meditation has been shown to foster a high degree of CS $(84,85)$ along with a parasympathetic response $(86,87)$. Stress is correlated with decreased CS and increased sympathetic tone (88). Thus, through techniques that allow for the voluntary modulation of CS, we suggest one may better manage stress.

\section{SLOW DEEP BREATHING}

Slow deep breathing techniques are some of the oldest and simplest techniques demonstrated to have a variety of 
therapeutic effects on the body and mind. The growing literature on the effects of slow breathing reveal benefits (89) for stress (90), affective mood disorder, asthma (91), and pain $(92,93)$, however, the literature on its effects on insomnia is minimal. Slower respiration corresponds to higher cardiorespiratory synchronization which as discussed, may promote parasympathetic tone (94). Slow, deep, regular breathing may attenuate the sympathetic component (95, 96) of hyper-arousal largely brought about by the frenetic nature of modern life (33) which may cause insomnia (10). Deeper breathing has been shown to result in stronger sympathoinhibition (97). In contrast, irregular and fast breathing have been shown to result in sympathetic excitation $(98,99)$. There is empirical support (13) that breathing at a frequency of $0.1 \mathrm{~Hz}$ is the most effective rate to combat insomnia as this rate initiates CS (100) and has been demonstrated to enhance parasympathetic activity (101). Practicing the $0.1 \mathrm{~Hz}$ rate before sleep was shown to improve sleep onset latency and quality in insomniacs and enhance the stability of their sleep pattern (13). Thus, we suggest $0.1 \mathrm{~Hz}$ as the optimal frequency for a slow breathing technique.

The efficacy of slow breathing techniques has been recognized by the military which use such techniques during combat situations to regain composure and reduce stress (102). Regular practice of a slow breathing technique overtime may provide long term correction of sympathetic over-arousal (96). In addition, slow, deep breathing has been shown to result in melatonin production which not only promotes relaxation (103), but is an essential sleep-inducing hormone (104) which promotes parasympathetic tone and inhibits sympathetic tone (105-107). Exogenous administration of melatonin can however lead to next-day drowsiness, headache, and/or dizziness (108). Melatonin levels are lower in insomniacs and much lower in long-term insomniacs, suggesting that the longer a sleep disorder exists, the more severe it gets (109). Sleep deprivation can result in increased sympathetic tone (56). This supports our view of a vicious cycle of worsening sleep deprivation (10); as sleep deprivation worsens stress, this may lead to further sympathetic hyper-arousal further worsening a sleep disorder.

Although out of the scope of this article, another mechanism by which we suggest slow deep breathing may treat insomnia has recently gained significant support, neural entrainment. Recent findings suggest that nasal respiration may act as a global organizer of neural oscillatory activity throughout the brain (110,

\section{REFERENCES}

1. Hori T, Sugita Y, Koga E, Shirakawa S, Inoue K, Uchida S, et al. Proposed supplements and amendments to 'A manual of standardized terminology, techniques and scoring system for sleep stages of human subjects', the Rechtschaffen \& Kales (1968) standard. Psychiatry Clin Neurosci. (2001) 55:305-10. doi: 10.1046/j.1440-1819.2001. 00810.x

2. Cologan V, Schabus M, Ledoux D, Moonen G, Maquet P, Laureys S. Sleep in disorders of consciousness. Sleep Med Rev. (2010) 14:97-105. doi: $10.1016 /$ j.smrv.2009.04.003
111). By modulating global network oscillations, respiration may exert control over cortical excitability (112). Such entrainment may provide a mechanism for breathing to alter brain waves, such as the increase in delta activity during slowed respiration (113). If respiration truly acts as a fundamental organizer of oscillatory brain activity $(111,112)$, then surely its modulation could be utilized to modulate brain activity to promote sleep.

\section{CONCLUSION}

In this perspective article, in agreement with a prevailing evolutionary mismatch hypothesis that hyper-arousal accompanied by sympathetic hyperactivation and parasympathetic hypoactivation is a major pathogenic mechanism of insomnia, we have suggested that modulation of the ANS via slow breathing techniques in adjunct to relaxation techniques and sleep hygiene may be a more powerful tool in combating insomnia than the prevailing method of using hypnotics and other pharmaceutical interventions. In respect to the close relationship between the ANS, sleep physiology, mental state, and respiration discussed, it is clear that people have or develop the ability to alter arousal levels voluntarily. We have proposed that slow breathing and other relaxation methods may attenuate the "mismatch disease" of autonomic hyper-arousal and help people deal with the arousing pressure to sleep. Although there is significant support for the efficacy of relaxation and sleephygiene techniques in treating insomnia, very limited research investigating treatment with slow, deep breathing. Through our perspective, we hope to inspire debate, discussion, and future research into insomnia as a "mismatch disease" and the effectiveness of slow breathing in attenuating autonomic hyper-arousal.

\section{AUTHOR CONTRIBUTIONS}

Theory developed by RJ with some writing with majority of the manuscript written by $\mathrm{CB}$. Editing and writing contributed by VB.

\section{FUNDING}

Funding provided by the Charitable Medical Healthcare Foundation.
3. Frank MG. The mystery of sleep function: current perspectives and future directions. Rev Neurosci. (2006) 17:375-92. doi: 10.1515/revneuro.2006.17.4.375

4. Watson NF, Badr MS, Belenky G, Bliwise DL, Buxton OM, Buysse D, et al. Joint consensus statement of the American Academy of Sleep Medicine and Sleep Research Society on the recommended amount of sleep for a healthy adult: methodology and discussion. Sleep (2015) 38:1161-83. doi: 10.5665/sleep.4886

5. Hargens TA, Kaleth AS, Edwards ES, Butner KL. Association between sleep disorders, obesity, and exercise: a review. Nat Sci Sleep (2013) 5:27-35. doi: $10.2147 /$ NSS.S34838 
6. Westerlund A, Bellocco R, Sundström J, Adami H-O, Åkerstedt T, Trolle Lagerros Y. Sleep characteristics and cardiovascular events in a large Swedish cohort. Eur J Epidemiol. (2013) 28:463-73. doi: 10.1007/s10654-013-9802-2

7. CDC. Short Sleep Duration Among US Adults-Data and Statistics. Sleep and Sleep Disorders (2017). Available online at: https://www.cdc.gov/sleep/data_ statistics.html

8. CDC. 1 in 3 Adults Don't Get Enough Sleep. CDC Newsroom (2016). Available online at: https://www.cdc.gov/media/releases/2016/p0215enough-sleep.html

9. Walsh JK, Coulouvrat C, Hajak G, Lakoma MD, Petukhova M, Roth T, et al. Nighttime insomnia symptoms and perceived health in the America Insomnia Survey (AIS). Sleep (2011) 34:997-1011. doi: 10.5665/SLEEP.1150

10. Basta M, Chrousos GP, Vela-Bueno A, Vgontzas AN. Chronic insomnia and stress system. Sleep Med Clin. (2007) 2:279-91. doi: 10.1016/j.jsmc.2007.04.002

11. Riemann D, Spiegelhalder K, Feige B, Voderholzer U, Berger M, Perlis M, et al. The hyperarousal model of insomnia: a review of the concept and its evidence. Sleep Med Rev. (2010) 14:19-31. doi: 10.1016/j.smrv.2009.04.002

12. Bonnet MH, Burton GG, Arand DL. Physiological and medical findings in insomnia: implications for diagnosis and care. Sleep Med Rev. (2014) 18:111-22. doi: 10.1016/j.smrv.2013.02.003

13. Tsai HJ, Kuo TBJ, Lee G-S, Yang CCH. Efficacy of paced breathing for insomnia: enhances vagal activity and improves sleep quality. Psychophysiology (2015) 52:388-96. doi: 10.1111/psyp.12333

14. Kales A, Kales J. Evaluation and Treatment of Insomnia. New York, NY: Oxford University Press (1984).

15. Tefft BC. Prevalence of Motor Vehicle Crashes Involving Drowsy Drivers, United States, 2009-2013. Washington, DC: AAA Foundation for Traffic Safety (2014).

16. Hafner M, Stepanek M, Taylor J, Troxel WM, Stolk CV. Why Sleep Matters - The Economic Costs of Insufficient Sleep: A Cross-Country Comparative Analysis. Santa Monica, CA: RAND Corporation (2016).

17. Daugherty J, Hendricks L, Simpson C. Sleep aids: sedative-hypnotic drugs in america. Natl Forum J Counsel Addict. (2014) 3.

18. Mendels J. Criteria for selection of appropriate benzodiazepine hypnotic therapy. J Clin Psychiatry (1991) 52:42-6.

19. Manconi M, Ferri R, Miano S, Maestri M, Bottasini V, Zucconi M, et al. Sleep architecture in insomniacs with severe benzodiazepine abuse. Clin Neurophysiol. (2017) 128:875-81. doi: 10.1016/j.clinph.2017.03.009

20. Treves N, Perlman A, Kolenberg Geron L, Asaly A, Matok I. Z-drugs and risk for falls and fractures in older adults-a systematic review and meta-analysis. Age Ageing (2018) 47:201-8. doi: 10.1093/ageing/afx167

21. Carlstedt RA. Handbook of Integrative Clinical Psychology, Psychiatry, and Behavioral Medicine: Perspectives, Practices, and Research. New York, NY: Springer Publishing Company (2009)

22. Kripke DF. Mortality risk of hypnotics: strengths and limits of evidence. Drug Saf. (2016) 39:93-107. doi: 10.1007/s40264-015-0362-0

23. Lemola S, Perkinson-Gloor N, Brand S, Dewald-Kaufmann JF, Grob A. Adolescents' electronic media use at night, sleep disturbance, and depressive symptoms in the smartphone age. J Youth Adolesc. (2015) 44:405-18. doi: 10.1007/s10964-014-0176-x

24. Devinsky O, Boesch JM, Cerda-Gonzalez S, Coffey B, Davis K, Friedman D, et al. A cross-species approach to disorders affecting brain and behaviour. Nat Rev Neurol. (2018) 14:677-86. doi: 10.1038/s41582-018-0074-z

25. Gluckman P, Hanson M. Mismatch: The Lifestyle Diseases Timebomb. Oxford, NY: Oxford Univ. Press (2013).

26. Lieberman DE. The Story of the Human Body: Evolution, Health, and Disease. New York, NY: Pantheon (2013).

27. Wheelwright J. From diabetes to athlete's foot, our bodies are maladapted for modern life. In: George S, editor. Discover. Waukesha, WI: Discover Magazine (2015). Available online at: https://discovermagazine.com/2015/ may/16-days-of-dysevolution

28. Giphart R, Vugt MV. Mismatch: How Our Stone Age Brain Deceives Us Every Day (And What We Can Do About It). London: Robinson Page (2018).

29. Wallace IJ, Worthington S, Felson DT, Jurmain RD, Wren KT, Maijanen $\mathrm{H}$, et al. Knee osteoarthritis has doubled in prevalence since the mid-20th century. Proc Natl Acad Sci USA. (2017) 114:9332-6. doi: $10.1073 /$ pnas. 1703856114
30. Berenbaum F, Wallace IJ, Lieberman DE, Felson DT. Modernday environmental factors in the pathogenesis of osteoarthritis. Nat Rev Rheumatol. (2018) 14:674-81. doi: 10.1038/s41584-0180073-x

31. Nesse RM, Bhatnagar S, Ellis BJ. Evolutionary origins and functions of the stress response system. In: Fink G, editor. Stress: Concepts, Cognition, Emotion, and Behavior. San Diego, CA: Academic Press (2016). p. 100.

32. Minguillon J, Lopez-Gordo MA, Pelayo F. Stress assessment by prefrontal relative gamma. Front Comput Neurosci. (2016) 10:101. doi: $10.10 .3389 /$ fncom.2016.00101

33. García-Martínez B, Martínez-Rodrigo A, Fernández-Caballero A, González P, Alcaraz R. Conditional entropy estimates for distress detection with EEG signals. Lect Notes Comput. Sci. (2017) 193-202. doi: 10.1007/978-3-319-59740-9_19

34. Weiss MD, Wasdell MB, Bomben MM, Rea KJ, Freeman RD. Sleep hygiene and melatonin treatment for children and adolescents with ADHD and initial insomnia. J Am Acad Child Adolesc Psychiatry (2006) 45:512-9. doi: $10.1097 / 01$ chi.0000205706.78818.ef

35. Gellis LA, Lichstein KL. Sleep hygiene practices of good and poor sleepers in the United States: an internet-based study. Behav Ther. (2009) 40:1-9. doi: $10.1016 /$ j.beth.2008.02.001

36. O'donnell S, Driller MW. Sleep-hygiene education improves sleep indices in elite female athletes. Int. J. Exerc. Sci. (2017) 10:522-30.

37. Bogdanov S, Naismith S, Lah S. Sleep outcomes following sleep-hygienerelated interventions for individuals with traumatic brain injury: a systematic review. Brain Injury (2017) 31:422-33. doi: 10.1080/02699052.2017.12 82042

38. Al-Kandari S, Alsalem A, Al-Mutairi S, Al-Lumai D, Dawoud A, Moussa M. Association between sleep hygiene awareness and practice with sleep quality among Kuwait University students. Sleep Health (2017) 3:342-7. doi: 10.1016/j.sleh.2017.06.004

39. Tsai S-L. Audio-visual relaxation training for anxiety, sleep, and relaxation among Chinese adults with cardiac disease. Res Nurs Health (2004) 27:45868. doi: 10.1002/nur.20039

40. Benson H. The Relaxation Response. New York, NY: William Morrow (1975).

41. Smith JC, Wedell AB, Kolotylo CJ, Lewis JE, Byers KY, Segin CM. ABC relaxation theory and the factor structure of relaxation states, recalled relaxation activities, dispositions, and motivations. Psychol Rep. (2000) 86:1201-8. doi: $10.2466 /$ pr0.2000.86.3c.1201

42. Song $\mathrm{C}$, Igarashi $\mathrm{M}$, Ikei $\mathrm{H}$, Miyazaki $\mathrm{Y}$. Physiological effects of viewing fresh red roses. Complement Ther Med. (2017) 35:78-84. doi: 10.1016/j.ctim.2017.10.001

43. Song C, Ikei H, Miyazaki Y. Physiological effects of visual stimulation with forest imagery. Int J Environ Res Public Health (2018) 15:213. doi: $10.3390 /$ ijerph 15020213

44. Miskiman DE. The effect of the transcendental meditation program on compensatory paradoxical sleep. In: Orme-Johnson DW, Farrow JT, editors. Scientific Research on the Transcendental Meditation Program: Collected Papers. Vol. 1. Maharishi European Research University - MVU Press (1972). p. 292-5.

45. Abrams AI, Siegel LM. The transcendental meditation ${ }^{\circledR}$ program and rehabilitation at folsom state prison:a cross-validation study. Correct Psychol. (1978) 5:3-20. doi: 10.1177/0093854878005 00101

46. Winbush NY, Gross CR, Kreitzer MJ. The effects of mindfulness-based stress reduction on sleep disturbance: a systematic review. Explore (2007) 3:585-91. doi: 10.1016/j.explore.2007.08.003

47. Martires J, Zeidler $M$. The value of mindfulness meditation in the treatment of insomnia. Curr Opin Pulm Med. (2015) 21:547-52. doi: $10.1097 / \mathrm{mcp} .0000000000000207$

48. Gong H, Ni C-X, Liu Y-Z, Zhang Y, Su W-J, Lian Y-J, et al. Mindfulness meditation for insomnia: A meta-analysis of randomized controlled trials. J Psychosom Res. (2016) 89:1-6. doi: 10.1016/j.jpsychores.2016. 07.016

49. Amutio A, Franco C, Sánchez-Sánchez LC, Pérez-Fuentes MDC, GázquezLinares JJ, Van Gordon W, et al. Effects of mindfulness training on sleep problems in patients with fibromyalgia. Front Psychol. (2018) 9:1365. doi: $10.3389 /$ fpsyg.2018.01365 
50. Garcia MC, Kozasa EH, Tufik S, Mello LEAM, Hachul H. The effects of mindfulness and relaxation training for insomnia (MRTI) on postmenopausal women: a pilot study. Menopause (2018) 25:992-1003. doi: 10.1097/gme.0000000000001118

51. Tooley GA, Armstrong SM, Norman TR, Sali A. Acute increases in nighttime plasma melatonin levels following a period of meditation. Biol Psychol. (2000) 53:69-78. doi: 10.1016/S0301-0511(00)00035-1

52. Cardoso R, De Souza E, Camano L, Roberto Leite J. Meditation in health: an operational definition. Brain Res Protoc. (2004) 14:58-60. doi: 10.1016/j.brainresprot.2004.09.002

53. Han KS, Kim L, Shim I. Stress and sleep disorder. Exp Neurobiol. (2012) 21:141-50. doi: 10.5607/en.2012.21.4.141

54. Miglis MG. Chapter 12-sleep and the autonomic nervous system. In: Miglis MG, editor. Sleep and Neurologic Disease. San Diego, CA: Academic Press (2017). p. 227-44.

55. Somers VK, Dyken ME, Mark AL, Abboud FM. Sympathetic-nerve activity during sleep in normal subjects. N Engl J Med. (1993) 328:303-7. doi: 10.1056/nejm199302043280502

56. Miglis MG. Autonomic dysfunction in primary sleep disorders. Sleep Med. (2016) 19:40-9. doi: 10.1016/j.sleep.2015.10.001

57. Cellini N, Zambotti M, Covassin N, Sarlo M, Stegagno L. Working memory impairment and cardiovascular hyperarousal in young primary insomniacs. Psychophysiology (2014) 51:206-14. doi: 10.1111/psyp. 12167

58. Irwin M, Clark C, Kennedy B, Christian Gillin J, Ziegler M. Nocturnal catecholamines and immune function in insomniacs, depressed patients, and control subjects. Brain Behav Immun. (2003) 17:365-72. doi: 10.1016/S0889-1591(03)00031-X

59. De Zambotti M, Covassin N, De Min Tona G, Sarlo M, Stegagno L. Sleep onset and cardiovascular activity in primary insomnia. J Sleep Res. (2011) 20:318-25. doi: 10.1111/j.1365-2869.2010.00871.x

60. De Zambotti M, Covassin N, Sarlo M, De Min Tona G, Trinder J, Stegagno L. Nighttime cardiac sympathetic hyper-activation in young primary insomniacs. Clin Auton Res. (2013) 23:49-56. doi: 10.1007/s10286-012-0178-2

61. Bonnet $\mathrm{MH}$, Arand DL. Heart rate variability in insomniacs and matched normal sleepers. Psychosom Med. (1998) 60:610-5. doi: 10.1097/00006842-199809000-00017

62. Castro-Diehl C, Diez Roux AV, Redline S, Seeman T, Mckinley P, Sloan R, et al. Sleep duration and quality in relation to autonomic nervous system measures: the multi-ethnic study of atherosclerosis (MESA). Sleep (2016) 39:1927-40. doi: 10.5665/sleep.6218

63. Farina B, Dittoni S, Colicchio S, Testani E, Losurdo A, Gnoni V, et al. Heart rate and heart rate variability modification in chronic insomnia patients. Behav Sleep Med. (2014) 12:290-306. doi: 10.1080/15402002.2013.801346

64. Nano M-M, Fonseca P, Vullings R, Aarts RM. Measures of cardiovascular autonomic activity in insomnia disorder: a systematic review. PLoS ONE (2017) 12:e0186716. doi: 10.1371/journal.pone.01 86716

65. Nofzinger E, Buysse D, Germain A, Price J, Miewald J, Kupfer D. Functional neuroimaging evidence for hyperarousal in insomnia. Am J Psychiatry (2004) 161:2126-8. doi: 10.1176/appi.ajp.161.11.2126

66. Perlis ML, Smith MT, Andrews PJ, Orff H, Giles DE. Beta/Gamma EEG activity in patients with primary and secondary insomnia and good sleeper controls. Sleep (2001) 24:110-7.

67. Steriade M, Mccormick D, Sejnowski T. Thalamocortical oscillations in the sleeping and aroused brain. Science (1993) 262:679-85. doi: $10.1126 /$ science. 8235588

68. Dhabhar FS, Saul AN, Daugherty C, Holmes TH, Bouley DM, Oberyszyn TM. Short-term stress enhances cellular immunity and increases early resistance to squamous cell carcinoma. Brain Behav Immun. (2010) 24:12737. doi: 10.1016/j.bbi.2009.09.004

69. Reisman S. Measurement of physiological stress. In: LaCourse JR, editor. Proceedings of the IEEE 23rd Northeast Bioengineering Conference (Durham, NH: IEEE) (1997). p. 21-3.

70. Glaser R, Kiecolt-Glaser JK. Stress-induced immune dysfunction: implications for health. Nat Rev Immunol. (2005) 5:243. doi: 10.1038/nri1571
71. Ben-Eliyahu S, Page GG, Schleifer SJ. Stress, NK cells, and cancer: still a promissory note. Brain Behav Immun. (2007) 21:881-7. doi: 10.1016/j.bbi.2007.06.008

72. Dequattro V, Hamad R. The role of stress and the sympathetic nervous system in hypertension and ischemic heart disease: advantages of therapy with beta-receptor blockers. Clin Exp Hypertens A (1985) 7:907-32. doi: 10.3109/10641968509077238

73. Damasio AR. The somatic marker hypothesis and the possible functions of the prefrontal cortex. Philos Trans R Soc Lond Ser B Biol Sci. (1996) 351:1413-20. doi: 10.1098/rstb.1996.0125

74. Wilson RA, Foglia L. Embodied cognition. In: Zalta EN, editor. The Stanford Encyclopedia of Philosophy. Stanford, CA: Spring 2017 ed. Metaphysics Research Lab, Stanford University (2017). Available online at: https://plato. stanford.edu/archives/spr2017/entries/embodied-cognition/

75. Damasio A. Somatic Markers and the Guidance of Behavior. New York, NY: Oxford University Press (1991).

76. Hamill RW, Shapiro RE, Vizzard MA. Peripheral autonomic nervous system.... In: Robertson D, Biaggioni I, editors. Primer on the Autonomic Nervous System. San Diego, CA: Academic Press (2012). p. 17-20.

77. Schacter D, Gilbert D, Wegner D, Hood B. Psychology: European Edition. London: Palgrave Macmillan (2011).

78. Cabiddu R, Cerutti S, Viardot G, Werner S, Bianchi AM. Modulation of the sympatho-vagal balance during sleep: frequency domain study of heart rate variability and respiration. Front Physiol. (2012) 3:45. doi: 10.3389/fphys.2012.00045

79. Bertisch SM, Wells RE, Smith MT, Mccarthy EP. Use of relaxation techniques and complementary and alternative medicine by american adults with insomnia symptoms: results from a National Survey. J Clin Sleep Med. (2012) 8:681-91. doi: $10.5664 /$ jcsm. 2264

80. Schafer C, Rosenblum MG, Kurths J, Abel HH. Heartbeat synchronized with ventilation. Nature (1998) 392:239-40. doi: 10.1038/32567

81. Bianchi AM, Ferini-Strambi L, Castronovo V, Cerutti S. Multivariate and multiorgan analysis of cardiorespiratory variability signals: the CAP sleep case. Biomed Tech (Berl). (2006) 51:167-73. doi: 10.1515/bmt.2006.029

82. Jerath R, Harden K, Crawford M, Barnes VA, Jensen M. Role of cardiorespiratory synchronization and sleep physiology: effects on membrane potential in the restorative functions of sleep. Sleep Med. (2014) 15:279-88. doi: 10.1016/j.sleep.2013.10.017

83. Bartsch RP, Schumann AY, Kantelhardt JW, Penzel T, Ivanov P. Phase transitions in physiologic coupling. Proc Natl Acad Sci USA. (2012) 109:10181-6. doi: 10.1073/pnas.1204568109

84. Cysarz D, Bussing A. Cardiorespiratory synchronization during Zen meditation. Eur J Appl Physiol. (2005) 95:88-95. doi: 10.1007/s00421-005-1379-3

85. Chang $\mathrm{CH}$, Lo PC. Effects of long-term dharma-chan meditation on cardiorespiratory synchronization and heart rate variability behavior. Rejuvenation Res. (2013) 16:115-23. doi: 10.1089/rej.2012.1363

86. Takahashi T, Murata T, Hamada T, Omori M, Kosaka H, Kikuchi M, et al. Changes in EEG and autonomic nervous activity during meditation and their association with personality traits. Int J Psychophysiol. (2005) 55:199-207. doi: 10.1016/j.ijpsycho.2004.07.004

87. Tang YY, Ma Y, Fan Y, Feng H, Wang J, Feng S, et al. Central and autonomic nervous system interaction is altered by short-term meditation. Proc Natl Acad Sci USA. (2009) 106:8865-70. doi: 10.1073/pnas.09040 31106

88. Zhang J, Yu X, Xie D. Effects of mental tasks on the cardiorespiratory synchronization. Respir Physiol Neurobiol. (2010) 170:91-5. doi: 10.1016/j.resp.2009.11.003

89. Russo MA, Santarelli DM, O'rourke D. The physiological effects of slow breathing in the healthy human. Breathe (2017) 13:298-309. doi: $10.1183 / 20734735.009817$

90. Everly G Jr., Lating JM (eds.). Voluntary control of respiration patterns. In: A Clinical Guide to the Treatment of the Human Stress Response. New York, NY: Springer New York (2013). p. 223-35. doi: 10.1007/978-1-4614-5538-7

91. Lehrer PM, Vaschillo E, Vaschillo B, Lu S-E, Scardella A, Siddique $\mathrm{M}$, et al. Biofeedback treatment for asthma. Chest (2004) 126:352-61. doi: $10.1378 /$ chest.126.2.352 
92. Sakakibara M, Takeuchi S, Hayano J. Effect of relaxation training on cardiac parasympathetic tone. Psychophysiology (1994) 31:223-8. doi: 10.1111/j.1469-8986.1994.tb02210.x

93. Meuret AE, Wilhelm FH, Roth WT. Respiratory biofeedbackassisted therapy in panic disorder. Behav Modif. (2001) 25:584-605. doi: 10.1177/0145445501254006

94. Porta A, Guzzetti S, Montano N, Pagani M, Somers V, Malliani A, et al. Information domain analysis of cardiovascular variability signals: evaluation of regularity, synchronisation and co-ordination. Med Biol Eng Comput. (2000) 38:180-8. doi: 10.1007/BF02344774

95. Seals DR, Suwarno NO, Dempsey JA. Influence of lung volume on sympathetic nerve discharge in normal humans. Circ Res. (1990) 67:130-41. doi: 10.1161/01.res.67.1.130

96. Pal GK, Velkumary S, Madanmohan. Effect of short-term practice of breathing exercises on autonomic functions in normal human volunteers. Indian J. Med. Res. (2004) 120, 115-121.

97. St. Croix CM, Satoh M, Morgan BJ, Skatrud JB, Dempsey JA. Role of respiratory motor output in within-breath modulation of muscle sympathetic nerve activity in humans. Circ Res. (1999) 85:457-69. doi: 10.1161/01.RES.85.5.457

98. Leung RS, Floras JS, Bradley TD. Respiratory modulation of the autonomic nervous system during Cheyne-Stokes respiration. Can J Physiol Pharmacol. (2006) 84:61-6. doi: 10.1139/y05-145

99. Kox M, Van Eijk LT, Zwaag J, Van Den Wildenberg J, Sweep FCGJ, Van Der Hoeven JG, et al. Voluntary activation of the sympathetic nervous system and attenuation of the innate immune response in humans. Proc Natl Acad Sci. (2014) 111:7379-84. doi: 10.1073/pnas.13221 74111

100. Yasuma F, Hayano J. Respiratory sinus arrhythmia: why does the heartbeat synchronize with respiratory rhythm? Chest (2004) 125:683-90. doi: $10.1378 /$ chest.125.2.683

101. Eckberg DL. Human sinus arrhythmia as an index of vagal cardiac outflow. J Appl Physiol. (1983) 54:961-6. doi: 10.1152/jappl.1983.54. 4.961

102. Grossman D, Christensen LW. On Combat: The Psychology and Physiology of Deadly Conflict in War and Peace. Millstadt, IL: Human Factor Research Group Inc (2011).

103. Harinath K, Malhotra AS, Pal K, Prasad R, Kumar R, Kain TC, et al. Effects of Hatha yoga and Omkar meditation on cardiorespiratory performance, psychologic profile, and melatonin secretion. J Alternat Complement Med. (2004) 10:261-8. doi: 10.1089/1075553043230 62257
104. Hardeland R, Pandi-Perumal SR, Cardinali DP. Melatonin. Int J Biochem Cell Biol. (2006) 38:313-6. doi: 10.1016/j.biocel.2005.08.020

105. Chuang JI, Chen SS, Lin MT. Melatonin decreases brain serotonin release, arterial pressure and heart rate in rats. Pharmacology (1993) 47:91-7. doi: 10.1159/000139083

106. Yildiz M, Sahin B, Sahin A. Acute effects of oral melatonin administration on arterial distensibility, as determined by carotid-femoral pulse wave velocity, in healthy young men. Exp Clin Cardiol. (2006) 11:311-3.

107. Pechanova O, Paulis L, Simko F. Peripheral and central effects of melatonin on blood pressure regulation. Int J Mol Sci. (2014) 15:17920-37. doi: 10.3390/ijms151017920

108. Heminger B, and Sheridan DJ. Could melatonin be the cure for sleepless nights? Nursing (2018) 48:69. doi: 10.1097/01.NURSE.0000527605.40086.d1

109. Hajak G, Rodenbeck A, Staedt J, Bandelow B, Huether G, Rüther E. Nocturnal plasma melatonin levels in patients suffering from chronic primary insomnia. J Pineal Res. (1995) 19:116-22. doi: 10.1111/j.1600-079X.1995.tb00179.x

110. Zelano C, Jiang H, Zhou G, Arora N, Schuele S, Rosenow et al. Nasal respiration entrains human limbic oscillations and modulates cognitive function. J Neurosci. (2016) 36:12448-67. doi: 10.1523/JNEUROSCI.2586-16.2016

111. Herrero JL, Khuvis S, Yeagle E, Cerf M, Mehta AD. Breathing above the brain stem: volitional control and attentional modulation in humans. J Neurophysiol. (2018) 119:145-59. doi: 10.1152/jn.0055 1.2017

112. Heck DH, Mcafee SS, Liu Y, Babajani-Feremi A, Rezaie R, Freeman WJ, et al. Breathing as a fundamental rhythm of brain function. Front Neural Circuits (2017) 10:115. doi: 10.3389/fncir.2016.00115

113. Busek P, Kemlink D. The influence of the respiratory cycle on the EEG. Physiol Res. (2005) 54:327.

Conflict of Interest Statement: The authors declare that the research was conducted in the absence of any commercial or financial relationships that could be construed as a potential conflict of interest.

Copyright (c) 2019 Jerath, Beveridge and Barnes. This is an open-access article distributed under the terms of the Creative Commons Attribution License (CC BY). The use, distribution or reproduction in other forums is permitted, provided the original author(s) and the copyright owner(s) are credited and that the original publication in this journal is cited, in accordance with accepted academic practice. No use, distribution or reproduction is permitted which does not comply with these terms. 